\title{
Community crosstalk: an exploratory analysis of destination and festival eWOM on Twitter
}

Article

Accepted Version

Williams, N. L., Inversini, A., Buhalis, D. and Ferdinand, N. (2015) Community crosstalk: an exploratory analysis of destination and festival eWOM on Twitter. Journal of Marketing Management, 31 (9-10). pp. 1113-1140. ISSN 1472-1376 doi: https://doi.org/10.1080/0267257X.2015.1035308 Available at https://centaur.reading.ac.uk/75362/

It is advisable to refer to the publisher's version if you intend to cite from the work. See Guidance on citing.

Published version at: https://doi.org/10.1080/0267257X.2015.1035308

To link to this article DOI: http://dx.doi.org/10.1080/0267257X.2015.1035308

Publisher: Taylor \& Francis

All outputs in CentAUR are protected by Intellectual Property Rights law, including copyright law. Copyright and IPR is retained by the creators or other copyright holders. Terms and conditions for use of this material are defined in the End User Agreement.

www.reading.ac.uk/centaur 
Central Archive at the University of Reading

Reading's research outputs online 


\section{Introduction}

The aim of this paper is to explore the nature of EWOM within a Community of Interest resulting from the staging of a hallmark event at a given destination. Hallmark tourist events have been defined as fairs, expositions, cultural and sporting events of international status held on either a regular or a one-off basis (Getz, Andersson, \& Carlsen, 2010). Even when these events are not immediately profitable and significant amounts of public investment are needed to stage these undertakings, losses will be absorbed on the grounds that the wider economic benefit of these events will exceed costs. One of these wider is support for development of tourism in the host community by increasing its visibility as a destination (O'Sullivan \& Jackson, 2002). As a result, event organizers have been interested on the rigorous collection and analysis of metrics relating to audiences scale and attention to be shared with destinations' and tourism managers (Grappi and Montarnari 2010) .

Advances in communication technology, especially related to online social networks, the availability of low cost communication devices in the form of smartphones and near ubiquitous data networks in developed countries, have supported the emergence of online discourses and narratives around events that are created and sustained by individuals (Mangold \& Faulds, 2009). These interactive narratives use the internet in a bidirectional way (Dellarocas \& Narayan, 2006) and are archived and shared online. Tourists interested both in the festival and in the destination may review the accounts of customers and events attendees (Blackshaw \& Nazzaro, 2006) a form of promotion that is based on online word of mouth or EWOM. However, at present, little effort is made to analyze these discussions which have great potential to enhance impact research done on events.

Previously researchers (Hauben \& Hauben, 1997; Rheingold, 1993) assumed that the internet would democratize access to information and promote a broad range of perspectives on any given issue by exposing users to views from outside their physical/offline social networks (McKenna \& Bargh, 2000). However, later research 
identified the filtering capabilities of the internet, or the ability of users to curate their information feeds (Gergen, 2008). This purposefully limits their perspectives to sources that match their interests. Analysis of these patterns can be used to infer the level of interest about a given topic such as politics (McPherson, Smith-Lovin, \& Cook, 2001). Nonetheless, it is not yet known if they have the same effect on hallmark events and festivals.

This research uses a Social Network Analysis (SNA) and text analysis approach to explore the structure and content of EWOM generated by a destination while a hallmark event is being staged (Echtner \& Ritchie, 1991). Data collection focused on the narratives created by the social network twitter.com. In order to collect the relevant information around a given event few steps have been done: first, the twitter.com conversations around this event were archived. Then, the community of interest was isolated by identifying replies, mentions and retweets within these tweets. The communities were modeled as a directed graph and then cluster analysis was applied to identify subgroups of users who were densely interconnected. These users interacted with users from their own cluster more than they connected to users in other clusters within the information network. Twitter.com profile information from subgroup members was used to classify each group in terms of the type of stakeholders participating in each discussion. The content of tweets sent by members in each cluster was also analyzed to identify the topic focus of each subgroup. An analysis of the resulting patterns was used to infer the overall impact of the festival and make recommendations for research and practice.

\section{Hallmark Events as a Destination Marketing Tool}

Events have been categorized by purpose including Public Celebration, Competition, entertainment, commerce or social interaction. In the field of tourism and the related disciplines of event management and event tourism, festivals are described as "... public, themed celebrations..." (Getz, 2005: p.21).

Festivals are distinguished from other types of special events by their purpose, which is the celebration or expression of the historical, social or cultural aspects of a particular 
host community (Getz, 2008). While this is still true for many festivals, an increasing number of festivals incorporate economic and promotional objectives to justify the costs of organizing for the tax payers (Gold \& Gold, 2005). Specifically, some festivals aim to attract cultural tourists that travel to visit heritage sites, attractions and cultural events(Quinn, 2010). They are generally high-income visitors who are well-educated and well-travelled and spend several nights at a destination (Smith, 2003).

In the tourism domain, festival research has followed three main strands (Page \& Connell, 2009)

1. Impact Studies that quantify the scale, purpose and outcomes (positive and negative) of festival tourism. In addition to direction of impact, this theme has broadened over time to go beyond financial impact evaluation to incorporate research into social and cultural impact of festivals.

2. Destination Studies which examine the use of festivals as destination attractions for potential visitors.

3. Operational Studies examine the issues encountered by destination managers in marketing and evaluating festivals.

While events have had a long commercial history, research on specific tourism benefits of festivals date from Ritchie and Beliveau (1974) on using events to reduce the impact of cyclical demand. Subsequent research went beyond buffering seasionalty to acting as a means to position venues, as is the case of mega events(Bos 1994) (Jago \& Dwyer,2006). Overall, research in this domain examines the direct and indirect financial impact of festivals. In the first area, research examines the ability of Events to attract new customers who consume services and products at the destination (Connell \& Page, 2009; Getz, 2008). Further, these event offerings can be used to target specific market segments to attract non traditional customers. For example, business events can be used to attract professionals while music festivals can target a young audience. Events also increase utilization of existing attractions, enabling destinations to operate more efficiently by reducing excess capacity. Cultural celebrations such as festivals and carnivals tend to utilize existing infrastructure and do not require purpose built 
facilities. Getz (2005) identifies four key ways in which events can be used to promote a destination. Firstly, as a place marketing tool, which involves packaging and promoting a place as a distinct product. It is a key ingredient in event led-regeneration and urban renewal because successful place marketing is critical if visitors are to be continually attracted or businesses to decide to make long-term investments in a destination (Sandercock \& Dovey, 2002 and Sassen, 1994) Secondly it can be used as a tourist attraction. Tourists can include persons be from overseas or from places just outside a particular destination. A key tourist segment that destinations will want to attract, is "cultural tourists". These are tourists that travel to visit heritage sites and attractions and cultural events (Quinn, 2010). They are generally high-income visitors who are welleducated and well-travelled and spend several nights at a destination (Smith, 2003). In addition to direct customer spending, events can act as an animator of existing tourism facilities, or historic sites. They can breathe new life into these places and create more economic and leisure options for locals. Finally, they can be an image maker for a destination which involves creating a distinctive image for a previously unknown destination or re-branding a destination. 


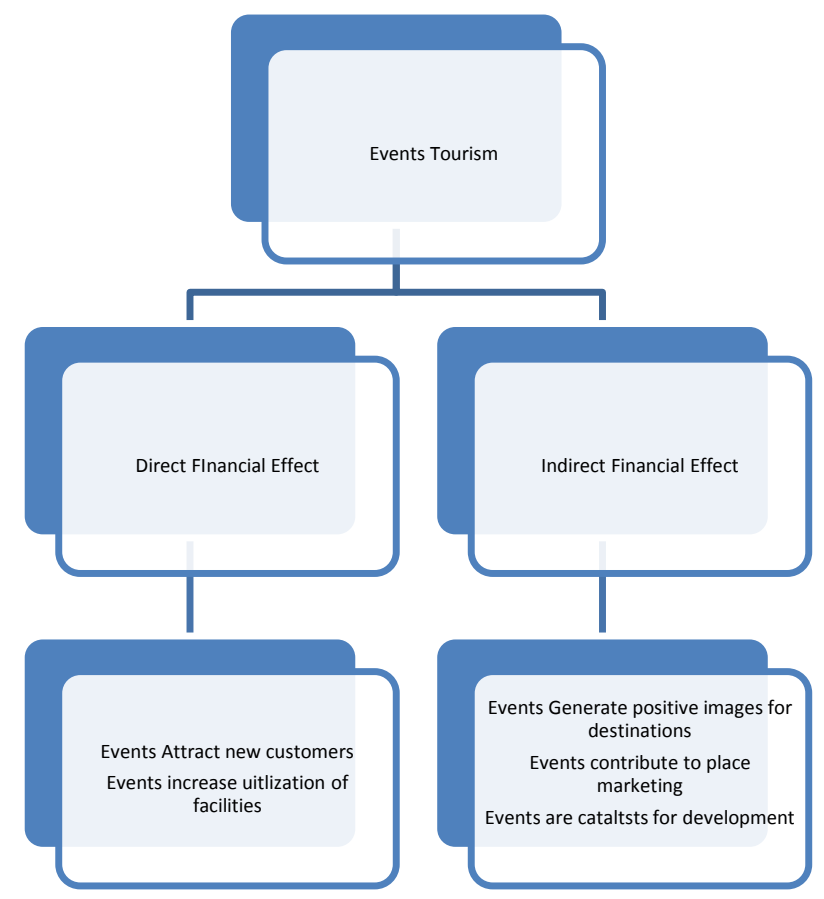

Events' ability to influence future customer purchases (Lee, Lee, \& Lee, 2005) may be based in their ability to create new memory connections within the minds of audiences (Elliot, Papadopoulos, and Kim 2011). These associations can be made via direct experience with the event, or indirectly via media information shared by the organizers and by the narratives of customers, i.e., word of mouth (WOM - Keller 1993). WOM involves consumers sharing attitudes, opinions or reactions about a business, product or service with other people (Jansen et al., 2009). WOM have always been a powerful and yet poorly manageable - marketing tool (Buttle 1998). Previous research has identified the ability of events to build new positive memory associations between the event and the destination via WOM (Gwinner, 1997). More recently the rise of the internet as a communication medium and the advent of social media has seen the emergence of a new phenomenon, 'eWord of Mouth' (eWoM - Hennig-Thurau et al., 2004) that has attracted a significant research interest from academics and practitioners. 
The advent of technologies, and the rise of the internet, revolutionized the tourism field by dramatically changing its competitive landscape (Buhalis, 2003). Since the early nineties the industry moved from the need of having an online presence (i.e. creating a website) towards a more ubiquitous and social presence (Fesenmaier and Xiang, 2014). Travellers are part of this ( $r$ )evolution as they are more and more exigent (Buhalis and Law, 2008) and in constant need of relevant information (Gretzel et al., 2006) to support their experience. Often information does not come by official information providers but by social media (Inversini and Buhalis, 2009), which are now populating search engines results (Xiang and Gretzel, 2010). Social media can be generally understood as internet-based applications that encompasses media impressions created by consumers, typically informed by relevant experiences, and archived or shared online for easy access by other impressionable consumers (Xiang \& Gretzel, 2010). Social media's ease of use and accessibility enable a wide range of users to share opinions (Dellarocas, 2003). They are currently the dominant platforms for hosting online communities of interest on personal and professional issues (Kietzmann, Silvestre, McCarthy, \& Pitt, 2012). Consumers are no longer passive recipients of information but they actively engage in peer-to-peer product recommendation and eWoM (Chu and Kim, 2011). In general terms, compared with traditional WOM, eWoM are (i) trustable as research found that people appear to trust seemingly disinterested opinions from other people outside their immediate social network (Duana et al., 2008); (ii) effective due to its speed, convenience, broadcast appeal and lack of pressure of face to face interaction (Sun et al, 2006); (iii) act as risk reducer tool towards an actual purchase (Litvin et al., 2008). Chu and Kim (2011) and Inversini and Masiero (2014) suggested that produc-focussed eWoM on social media it is a unique phenomenon with important social and commercial implications.

Social media are a popular research topic in the tourism field (Luo and Zhong, 2015): to date research focused on two main topics:

(i) the role played by social media as information sources for travellers (Blackshaw \& Nazzaro, 2006). Social media are increasingly dominating search engine results (Hays, 
Page, \& Buhalis, 2013) and traditional providers of travel-related information have been required to include social media in their online marketing (Xiang \& Gretzel, 2010).

(ii) the reasons to share information on these networks. Individuals younger than 35 years old, with at least a college degree actively participate in social media sharing (especially for what concerns pictures - Lo et al., 2011). Nonetheless there can be three main functional motivations to share informations on social media, namely: (i) obtaining travel information, (ii) disseminate travel information and (iii) documenting personal experiences (Huang et al., 2010)

Crucially, in addition to ubiquity, customer narratives hosted on social media(Dellarocas, 2005) may be seen more authentic than other forms of promotion (Hanna et al., 2011). By blurring the lines between consumers and allies and partners (Wang et al., 2002), information posted on social media may be more influential as other sources as consumers tend to trust more other users' recommendations as opposed to marketing messages (Jain, 2008). Therefore, by presenting a consumer influenced narrative about destinations these discussions can create impressions that can influence consumers' actions (Bikhchandani et al., 1992; Foster and Rosenzweig, 1995; Godes and Mayzlin, 2004)

Since tourism is an experiential product, customers heavily rely on previous experiences and recommendations from other travellers who already experienced the actual product (Haywood, 1989). However, if on the one hand social media are great information sharing platforms $(X X X X)$ and customers are taking advantages from the eWoM (XXXX) on business level consumers are spreading opinion-based information that potentially can affect the company's image (Jung et al, 2013). This raises a potential challenge for destination managers (e.g. Baloglu and McCleary, 1999) if these narratives are negative (Munar, 2011) and since they are seen as more legitimate, may damage the destination's competitive. However, while events may act as an influence on destination related WOM and EWOM, to date, little is known about the nature of this influence. 
In addition, social media provides a great opportunities to engage products and services in real time and to provide live information. This is particularly useful when the context is volatile with issues such as traffic, weather, availability of resources improving service delivery and influencing the customer experience. Social media can therefore enhance cocreation through a high degree of the interactivity and co production.

\section{Social Media Communities of Interest to understand Destination Image}

An opportunity to investigate the impact of social media with respect to EWOM lies in the analysis of the narratives created online communities of interest around destinations and events. In addition to the advantages provided for promoters and marketers, the disruptive rise of the internet present an incredible opportunity for tourism and events researchers as many of the discussions about travel, destinations and tourism now occur online in a form that can be archived and analysed (Neuhofer, Buhalis, \& Ladkin, 2012). It provides the potential to provide deep insights into customers' perceptions of TDI. Further, due to the number of individuals using these platforms, it is possible to compare a number of perspectives on the issue (Zaglia, 2013).

Since the emergence of communities based on interest, information and affection, researchers have sought ways of classifying them. From a marketing perspective, companies may attempt to create or encourage their development, using specific platforms with their product or brand at the core (Wirtz et al., 2013). These network communities have been defined by the structured social relationships created by fans, customers or admirers (Muniz Jr \& O'guinn, 2001). These communities can be online or offline (Muniz \& O'Guinn, 2001), small (Bagozzi \& Dholakia, 2006) or large (Adjei, Noble, \& Noble, 2010). Members may also share distinct values, behaviours patterns of language and signals (Muniz \& O'Guinn, 2001). Further, beyond common beliefs, members may feel moral responsibility for supporting members and integrating new members into the community. This is the core of an online community as these categorizations define the nature and extent of their activities, allowing them to identify members and non members (Bagozzi \& Dholakia, 2006). It defines and structures the community experience and allows members to assign meaning to their activities that they then communicate to others (Casaló, Flavián, \& Guinaliu, 2008). 
In the online domain, these communities can serve several purposes (Hagel and Armstrong 1997) including (1) interest, (2) relationship building, (3) transaction, and (4) fantasy. Communities of interest agglomerate individuals with a shared interest (Brown \& Duguid, 2001) while Communities of Relationships connect individuals who need to share personal experiences such as health concerns. Communities of transactions are focused on financial or economic exchanges while Communities of fantasy provide the opportunity for individuals use imagined identities to interact in a fantasy setting (Rothaermel \& Sugiyama, 2001).

For this research, online communities of interest provide an opportunity for understanding interactions around a destination. In these communities, members combine content and communication to learn about and to share knowledge about a given area (Obst, Zinkiewicz, \& Smith, 2002). Online communities have gone further to modify product offerings to create new experiences (Harwood \& Garry, 2010). Several factors influence the nature of the interaction that members will have in these communities. The size of the group can positively influence the amount of content created or shared and hence the benefit that individuals will gain from membership. Group heterogeneity also positively influences the amount of contributions and benefits to members (Oliver, Marwell, \& Teixeira, 1985). Communities with these characteristics can be seen as more attractive to non members who are seeking to understand a given topic or issue. For events and tourism research, it suggests that the scale and the composition of the online community that discuss their experiences can shape perceptions by non visitors and hence influence visit behavior.

Using Communities of Interest hosted on Social Media to understand Online Destination Engagement: Content, Structure and Key Users

For this research, the community of interest created on twitter.com were analysed. The research builds upon the on-going discussion in marketing research about the use of social media (and especially twitter.com) as marketing tool, for example as a CRM tool (Canhoto and Clark, 2013) or as a relationship-marketing tool (Jung et al., 2013). While there are other popular social media sites such as Facebook, twitter has some advantages and has been used in research in a number of fields including politics, 
business, sociology and epidemiology (Hardin, 2014). Data obtained from twitter has also been used to examine promotional strategies of destination organizations (Sevin, 2013). Unlike Facebook, tweets are public by default (Marwick \& Boyd, 2010) and users do not need to have any direct relationship with each other in order to view and interact with content. Twitter users are therefore able to engage in information seeking and response behavior with a wider population of individuals than would be available from a platform with a mix of public and private discussions such as Facebook or Google Plus (Kwak et al 2010).

\section{How Twitter Works}

Twitter (twitter.com) can be best described as a microblogging network that enables users to post updates known as tweets that are limited to 140 characters and can include images or links to other websites. Users sign up for accounts that begin with "@" to share tweets which are public by default with the exception of users who have chosen to "protect" their posts. To view the tweets of others, Twitter users can choose to "follow" other accounts. Information interactions on Twitter include replies, mentions and retweets. Replies are a public message to a particular user that begins with the recipient's account @. Mentions are posts that contain the name of a users within the message, but not at the beginning as in the terms of Replies. Finally, retweets are the resharing of another users' tweets to the accounts that follow your account. Hashtags ( \#) are a means of organizing content on twitter. Users who are following or monitoring the hashtag can see these postings even if they do not follow the user generating the tweet.

\section{Twitter and COI Research}

The public nature of Twitter therefore enables researchers to generate insights without violating the legal or moral wishes of other users. Further, since a complete $\mathrm{CO}$ can be obtained, this enables the detailed analysis of subgroups within a given the population, an advantage for destination and event research as their populations tend to be heterogeneous rather than homogenous. Further, unlike other social platforms that are limited to specific mobile operating systems (smartphones) or require mobile bandwidth, 
Twitter.com updates can be sent from a wide variety of devices, ensuring that updates are sent immediately. By eliminating the delay between observation and communication, Twitter.com updates may be more authentic as less rationalization and information processing is done by the user (Vega, 2011). Further, analysis of twitter postings or tweets indicate that rather than being merely personal, the content resembles a social history of the topic of interest incorporating factual data, opinions and interactions (Humphreys, Gill, \& Krishnamurthy, 2013). This is an advantage for destination and event research as it provides a range of information that can be used to extend knowledge in the field.

These advantages are necessary when examining COls. Since participants of COls may be heterogenous in terms of demographics or geography, it is necessary to obtain a large sample, or if possible a census of all discussions in order to ensure that a wide range of perspectives on the topic are obtained. Further, it assists researchers in understanding the structure of the $\mathrm{COI}$ as it is possible to gain a holistic view of interactions within the network. Due to it's public nature, Twitter supports this process (Williams et al. 2014) without violating the wishes of individuals who intended to keep their postings private. By contrast, while Facebook is a larger network, a significant amount of it's content is intended to be shared with individuals "friends" with which the sender has a defined relationship. Research that seeks to examine a COI hosted on Facebook or Google Plus will face difficulty as a number of these posts would be private and unavailable for analysis. Further, while these platforms are commercial spaces owned and controlled by corporations, even research conducted by them has been widely criticized. For example, Facebook has come under government scrutiny for experiments conducted on a large sample of it's user base.

\section{Social Network Analysis and COI}

To evaluate the nature of interactions and discussions of stakeholders in COls, Social network analysis (SNA) may be an appropriate approach. SNA takes the perspective that between individuals form the building blocks of social institutions (Scott, 1988) . Aggregated, these interactions form social networks within families, communities, organizations or countries that transmit information, distribute resources, coordinate 
activities and manage social norms (Latour, 2005). In SNA, they are conceptualized as nodes and connectors (Hogan, Carrasco, \& Wellman, 2007). Nodes represent entities such as families, cities, companies or countries. Connectors are ties between nodes that can be classified by similarity, relationship, interaction or flow (Borgatti, Mehra, Brass, \& Labianca, 2009). For COls hosted on Twitter, nodes are twitter accounts and connectors are the information relationships implied by retweets, replies and mentions.

Figure 1: Links in Social Networks

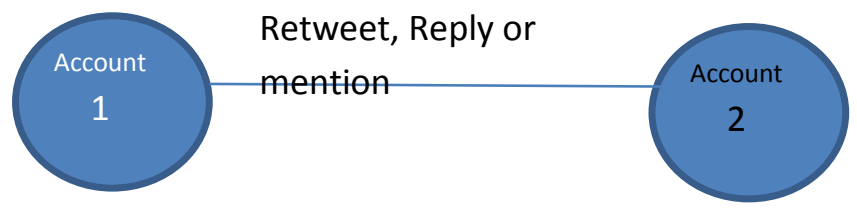

Analysis of these networks have drawn from a number of fields including mathematics, social science and physics (Baggio, Scott, \& Cooper, 2010). The mathematical approach was adapted from graph theory and uses models of ideal networks to examine structural characteristics and resulting properties such as patterns of information diffusion. SNA has also been used in a drawn from the social sciences that uses networks as a qualitative means of visualizing relationships between actors in social settings. Finally, approaches have been adapted from physics to examine complex emergent phenomena.

While the study of these networks began in the 1800s, recent advances in information technology have made it easier to collect and analyze social network data. The advantages of this approach in marketing is that it can examine the nature, extent and interactions between large numbers of stakeholders at a scale that was not imaginable 10 years ago (Mohan \& Paila, 2013).

SNA enables the identification and analysis of a range stakeholder groups that exist within COls in since stakeholders are not monolithic, but contain many subgroups with their own particular interests and perspectives (McLeod, Doolin, \& MacDonell, 2012). Specifically, it enables the evaluation of network structure which influences the way in 
which information can flow within a COI. For COls, networks may contain clusters or groups of nodes who share more relationships with each other rather than the rest of the network (Scott, 2000). Information will therefore flow between these nodes more than the rest of the $\mathrm{COI}$ and members of these subgroups.

Information flow is also influenced by Node properties. Centrality, or the relationship of a given node to other nodes in the network is one such property. Nodes with a high degree of centrality are linked to a larger number of nodes and information shared by them will more prominent than information shared by less central nodes (Wasserman and Faust, 1994). Central nodes have a high degree of influence as they act as information brokers, connecting actors within and across clusters.

\section{Benefits of using COI hosted on Twitter}

While EWOM researchers have begun to examine social media, they have used it primarily as a means to gain respondents for conventional quantitative or qualitative research. For the former, Wolny and Mueller (2013), used a survey methodology to evaluate the nature of customer motivation to engage in EWOM sharing or seeking. Others have examined the nature of user (Canhoto and Clark 2013) or hotel owner ( Jung et al. 2013) using interviews of social media users. More recently, research has directly sought to understand EWOM using manual content analysis (Lasarte 2014). However, these approaches work with a relatively small subset of the data available from social media and analysis of a complete community of interest has the potential to develop useful insights for marketers. Specifically, it enables researchers to uncover influential individuals within the $\mathrm{COI}$ along with the content that is seen as most valuable.

Similarly, while SNA has been previously applied in tourism and marketing research, previous work have used survey based methods that do not enable the evaluation of a complete network. SNA has been previously applied to understand stakeholder interactions in destinations and larger networks in product and service communities. However, in those cases, data was collected and analyzed manually. The networks were therefore based on a sample of possible interactions which may result that the 
perspectives of some stakeholders were not captured Emerging work on twitter have primiarily been qualitative analysis of tweet content, with little consideration of connections between individuals. Since no research of this nature has been conducted before ,the paper takes an exploratory study to establish validity of SNA clustering approach and subseuent text analysis approach..

\section{Research Questions}

This research has been designed to explore the structure and content of online narratives shared within a COI hosted on twitter around a destination when a hallmark event is staged. Since research in the area of EWOM and SNA have adopted traditional qualitative or quantitative approaches, it is first necessary to understand the nature of relational structures formed in the COI. Social media facilitates new forms of organization among users, creating relational structures that do not face the same constraints as traditional social structures (Ma \& Agarwal, 2007; Schultze \& Orlikowski, 2010). Research suggests, however, that user interactions via online spaces generally form a skewed distribution or a power-law distribution of connections among users (Newman, 2001), where a few users attract a large and disproportionate number of social and informational ties (Huberman, Romero, \& Wu, 2008). These connections are identified through information sharing activities by users of retweeting, replies or mentions. Within this network, or $\mathrm{COI}$, users can create subgroups in which connections within the subgroup are denser than outside the subgroup (Carrington, Scott, \& Wasserman, 2005).

On twitter.com, a small number of users, also called hubs, are likely to attract a large number of followers, mentions, and replies. Analysis of these hubs may enable the identification of stakeholder groups (e.g. 'visitors') in the overall destination community of interest. In this way, it is possible to identify groups based on their behaviour within the network, or in an inductive manner. It is therefore possible to conduct analyses based on the interests and actions of online stakeholders of the event and destination, 
rather than working with an a priori designation that may not be appropriate for the destination under study.

While distinct hubs of this nature have been identified in previous research in politics and marketing research (Himelboim, Smith, \& Shneiderman, 2013), it is still not known if similar patterns exist when evaluating events and festivals. The first research question is therefore:

RQ1: Do the festival and destination online COls form distinct stakeholder clusters?

While social media platforms enable peer-to-peer connections by individuals, many dominant members of online communities are media industry professionals and celebrities (Graeff, Stempeck, \& Zuckerman, 2014). For WOM and EWOM, the source of information is as important as the content of the message itself. If the source is seen as lacking in legitimacy, the message may be ignored and EWOM will not be developed(Wu, Hofman, Mason, \& Watts, 2011). It is therefore necessary to understand the characteristics of key actors in these hubs to identify if the narratives are developed and sustained by individual visitors and residents or are a part of a larger framing by commercial or activist organizations (Loader, Vromen, \& Xenos, 2014). The presence of the latter may indicate that the festival is merely an extension of existing marketing efforts while the former may suggest that a peer to peer $\mathrm{CO}$ between potential and current visitors was developed. In addition to background, geographic location is also important. Community festivals for example, will have primarily a local or regional audience (Getz, 2008) while international festivals may have a wider geographic range of physical and possibly online participants. This may be reflected in the characteristics of the key individuals who are discussing the festival on social media. It is therefore necessary to identify if key users within the overall COI engage with a local audience or 
if they are able to engage with an international one as a means of evaluating the geographic reach of the online discussions about the destination and festival.

The research question as a result is:

RQ2 What are the characteristics of critical stakeholders in these clusters?

In addition to the nature of users who are discussing the festival and event on twitter, the content of their discussions can also indicate if the festival stimulated engagement by potential visitors. In the tourism field it has been noted that with the advent of social media there is an information competition between official and unofficial destination websites (Inversini et al., 2009). Information is present on official websites (e.g. destination websites) but also on social media (e.g. social networks, blogs). Social media are spreading tourism information including recommendations and experiences and may result in differing perspectives on TDI (Inversini and Buhalis, 2009). The reason for this could be that websites are the online representation of a destination's marketing campaign and the organizations that manage these websites have similar views on what customers are seeking (Hamid-Turksoy, Kuipers, \& Van Zoonen, 2013). However, customers are not homogenous and their perspectives on a destination may vary from official representations (Sun, Ryan, \& Pan, 2014). User generated content in the form of blogs and social media accommodates these views (Lim, Chung, \& Weaver, 2012). As a result, the topics discussed by customers may encompass a wider range of interests and overall, create an emergent TDI that varies from official representations (Guerrero-Solé \& Fernández-Cavia, 2013). An analysis of the narratives within stakeholder groups on social media can enable us to understand this user generated perspective on TDI resulting in the below question:

RQ3: What are the topics of discussion within these clusters?

\section{Methodology}

In order to tackle the above presented research question, a study of the twitter.com conversations of a tourism destination and of an event happening within the destination 
has been carried out. The chosen destination is Bournemouth and the event was the Bournemouth Air Festival 2013. Bournemouth a prominent coastal destination in the UK.

Situated in the south coast of England, Bournemouth has a 200 year history as a purpose built resort (Bournemouth.co.uk). There are some 15,500 bed spaces in Bournemouth and over 100 attractions and places of historical interest within a one hour drive time. The visitor economy employs 1 in every 6 people in Bournemouth and generates a gross income exceeding $£ 500$ million every year. In 2008, Bournemouth created a new annual event in the Bournemouth Air Festival. The event draws an estimated audience of 1.4 million over the four days and three nights and also has an economic impact of $£ 30 \mathrm{~m}$ Bournemouth Air Festival audience, comprises locals as well as visitors from across the UK and Europe, attracts $A B C 1, C 2$ and $D$ (middle class and lower class) people of all ages and social groups (Bournemouthair.co.uk).

Not only Bournemouth festival is one of the largest in the UK, but it requires a high degree of live coordination and communication via social media as contextual factors influence the program and customer satisfaction. As an outdoor event that depends on the performance of stunt aircraft, weather is of paramount importance as it determines the type of aircraft that can operate, the nature of acrobatics and the type of stunts performed. Further, crowd control is critical as organizers wish to communicate with festival goers to update them on the changing program and engage them with conversation in real time. Access to data and inside information is another factor that influence the issue of location.

\section{Research Methodology}

Research into COls is highly complex as perspectives at the macro (structural features of community) and micro level (individual actors) interact (Baloglu \& McCleary, 1999). The analysis of destination imaged perception is also a challenge as the researcher is required to integrate an heterogeneous group of data sources into an overall assessment of TDI (Pettigrew, 1997). For this type of research, case studies can be deployed as they have the ability to incorporate a wide range of evidence and 
methodologies, both qualitative and quantitative, which is useful in this research. The research adopts a exploratory nested case approach (Voss, Tsikriktsis, \& Frohlich, 2002) that combines SNA and text analysis to examine the community of interest at both the event and the destination. Figure 1 provides an overview of the exploratory case study:

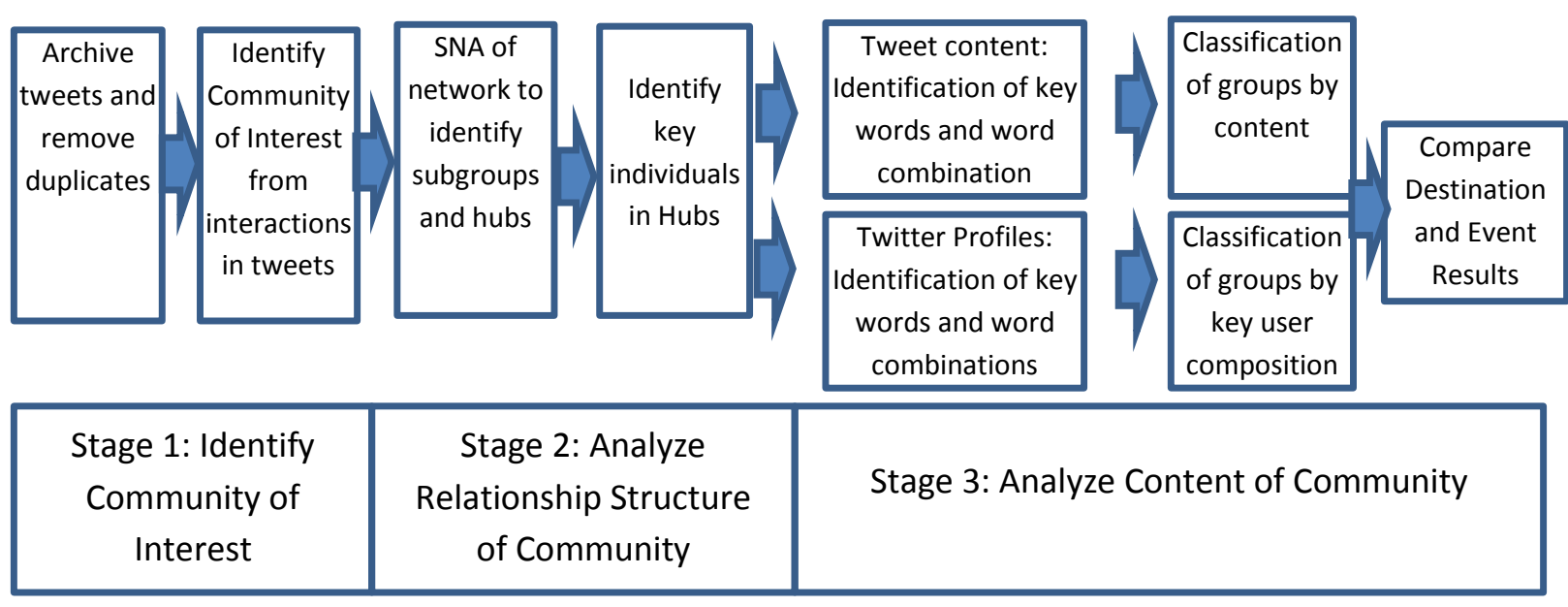

Figure 2 Overview of the exploratory case study

\section{Stage 1: Identification of Community of Interest}

In order to operationalize social network analysis a series of search terms and hashtags were selected that captured the online narrative about the event and the destination. While current twitter.com research relies heavily on postings organized by hashtags (Weber, Garimella, \& Teka, 2013), users may post without these tools. To ensure that a wide range of online narratives were captured, we also used search terms to archive relevant tweets that did not have those hashtags. For the event, postings related to search terms "Bournemouth Air Festival" and "Bournemouth Air Show" were archived along with the event hashtags promoted by the organizer of "\#BmnthAirFest" and "\#NightAir". For the destination, we used the search term "Bournemouth" and \#bournemouth. Terms were archived for one month before (August $1^{\text {st }}$ ) to one month after the event (September $31^{\text {st }}$ 2013). However, an analysis of the traffic (Figure 3) since there was little event specific traffic before the week before (August $22^{\text {nd }} 2013$ ) the event to the week after the event (September $9^{\text {th }}$ 2013), later analysis focused on this period. 
Figure 3: number of collected tweets over time

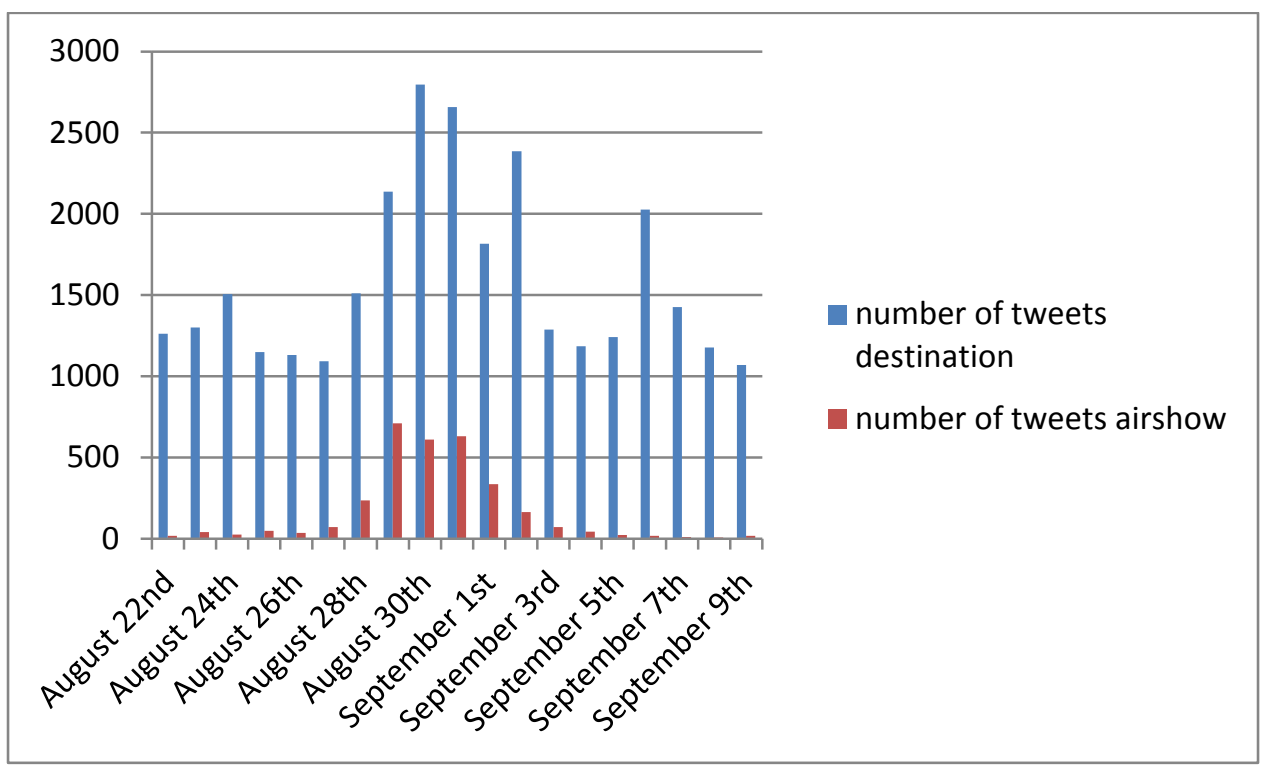

Next, event and destination tweets were then consolidated and duplicates in each category were removed.

\section{Stage 2: Analysis of the relationship structure of the community}

Tweets were then filtered to identify the underlying information relationships between users in the form of 'Replies', 'Retweets' and 'Mentions'. These forms of relationships, between users were then modelled as an unweighted directed graph using social network analysis at the next stage. Finally, we examined the extent to which each network was linked to each other by examining the number of Event information network members that also belong to the overall Bournemouth network.

The social network was then analysed using the open source SNA tool Gephi (Gephi.org). Gephi is a free tool that enables the generation and analysis of social networks. Further, Gephi has a number of plugins that can be used to perform different types of analyses. Gephi was used to identify underlying clusters using the Clauset Newman-Moore (Clauset, Newman, \& Moore, 2004) clustering algorithm, selected for its ability to analyze efficiently identify subgroups in large network data sets. The distinctiveness of topic communities in the information network was identified using the modularity statistic (Newman, 2004). In Newman's (2004) measurement of modularity, 
values range between zero and one with higher values indicating more distinct topic clusters. Further work (Wang 2012) has indicated that 0.4 is a sufficient metric for identifying clusters and beyond 0.6, clusters do not exhibit further meaningful distinctiveness.

This research will therefore use 0.4 as a basis for accepting that meaningful clusters exist and 0.6 to indicate a high degree of clustering. Once the existence of clusters was confirmed, they were then ranked by size or the number of users assigned to each. After ranking the top 20 key hub users were identified using betweeness centrality measure: This measure indicates how prominent each user is in terms of the exposure to users' posted content (Dugué \& Perez, 2014).

\section{Stage 3: Content Analysis in the Community of Interest}

Text analysis was then performed on the content of the tweets within the clusters. An inductive approach was followed in which the initial findings were used to guide subsequent analysis. This approach was followed to ensure that the analysis captured the unique aspects of the destination as discussed by online stakeholders. Keyword analysis was first performed on both the twitter content and profiles of key individuals of each hubs (i.e. the most representative nodes in the network by means of mention, retweet, favourites and reply) to identify frequently used words using the Voyant (Voyant-Tools.org) an open source package that analyses text data. Voyant was used to analyse the text using the following statistics: frequency, $Z$ score and normalized use per 10,000 words. These statistics were used to enable comparison across hubs which may have different volumes of discussion (Graesser, Jeon, Yan, \& Cai, 2007). The highest ranked 100 words by raw and normalized frequency were identified in each hub and reviewed to determine terms that relate to specific Bournemouth destination elements. Once identified, keywords that related to destination elements such as "Beach" and "Pier" were reviewed qualitatively further using a keyword in context tool to understand the nature and intent of discussions around keywords (Leech \& Onwuegbuzie, 2007). The combined output from the social network analysis and text 
analysis was used to classify the groups in both the Destination Community of Interest and the Destination Community of interest.

While the use of social network sites such as twitter.com for research purposes, is relatively new, this research adopts several suggestions made by previous research to improve validity (Tufekci, 2014). The first is that data collection did not focus on hashtags only, but incorporated search terms to ensure that all relevant data would be captured (Bruns \& Stieglitz, 2012). The second was the utilization of multiple methods to compensate for the weaknesses of any single approach (HerdaĞdelen, Zuo, GardMurray, \& Bar-Yam, 2013).

\section{Results}

Following the research design above outlined, a data set containing a collection of tweets related to Bournemouth Air Festival and to Bournemouth as tourism destination was created. Monitoring started one week before the festival and ended one week afterward. The data set related to the event contained 3121 tweets while the dataset related to Bournemouth as destination resulted in 30161 tweets. Figure 2 indicates that the Air Festival made up $10 \%$ of all interactions during the period with the most significant effect during the days in which the air show was staged. These interactions were then modelled as a directed graph with the characteristics below. Figure 3 shows the representation of the destination social network, while Figure 4 shows the representation of Bournemouth Air Show Social Network.

Figure 4: Destination Social Network. Modularity: 0.756965 


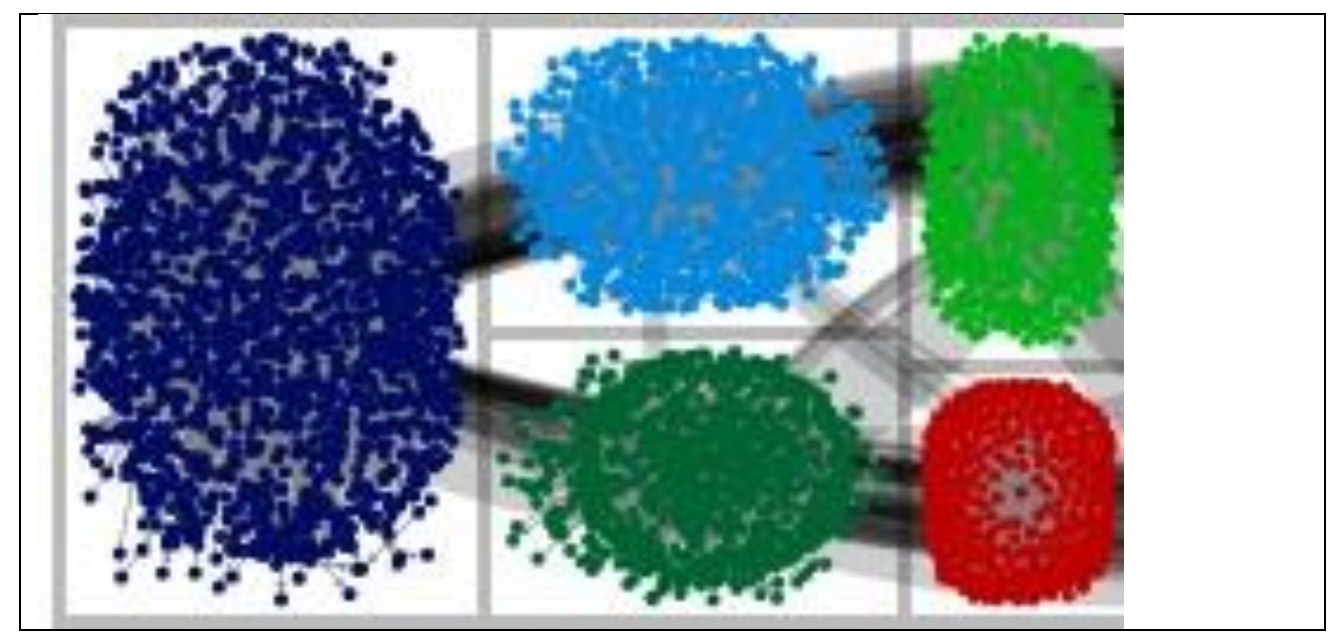

Figure 5: Bournemouth AirShow social network. Modularity: 0.582485

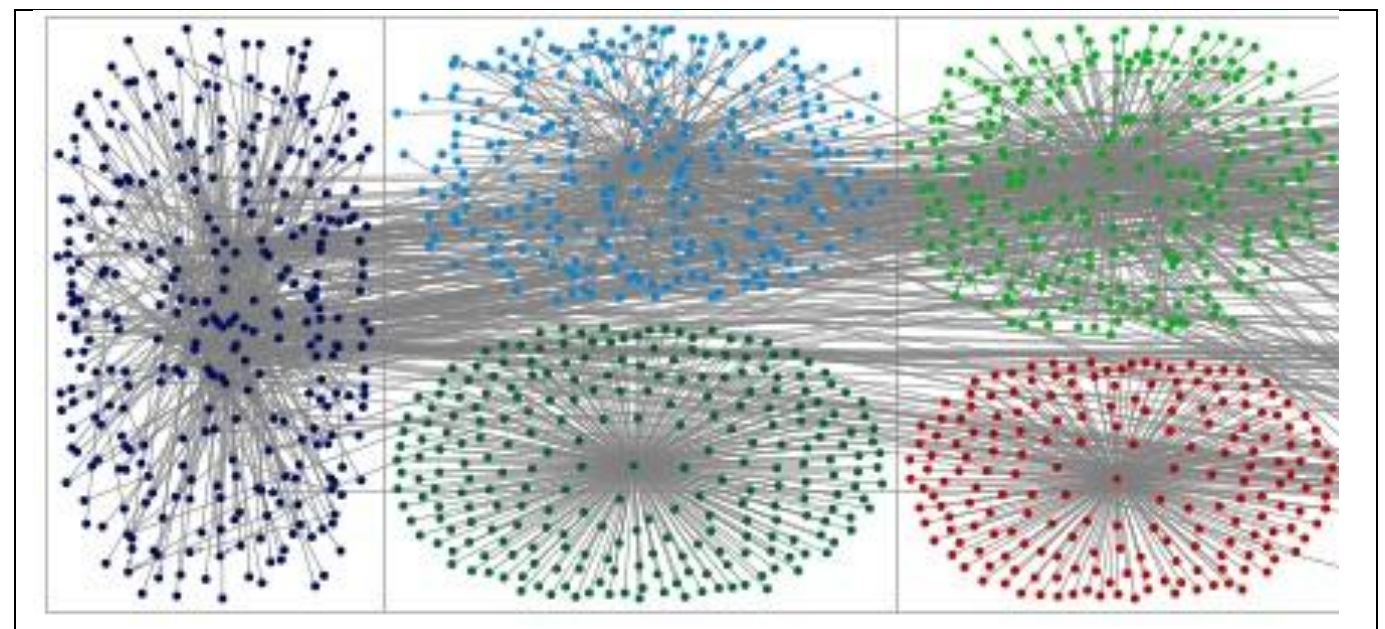

Social network overview

The two representations show 27982 vertices (i.e. number of users) for Bournemouth as destination and 2158 vertices for the air show with a number of unique edges (unique tweet content) of 23524 and 2066 respectively. Bournemouth as tourism destination is represented by 30102 total edges, while Bournemouth airshows counts 3199 of them.

Finally, results indicate that both networks show a high degree of modularity $(0.756965$ and 0.582485 respectively), indicating that distinct hubs were formed. The maximum number of vertices in a connected component, i.e. the number of accounts connected 
to a single user, is composed by 11034 and 1501 edges respectively. Each group in the above diagram represents a cluster with larger clusters on the left. The top 5 clusters are presented for each network.

Focusing on the above elaborated research questions, the analysis is as it follows.

RQ1: Do the festival and destination online COls form distinct stakeholder clusters?

In response to research question one, measurements of modularity indicate that users form medium to high levels of cluster separation when contributing to a given destination related topic on Twitter. We used the Clauset-Newman-Moore algorithm to analyze and cluster the network into subgroups. For the air show the top two clusters, -one with 1104 users linked by 2131 connections and the other with 312 users linked by 513 connections accounted for $70 \%$ of all connected users and $63.8 \%$ of all relationships in the network. The modularity value for these clusters was .58 , suggesting a high level of separation among clusters. For the destination, the top two clusters account for less than $20 \%$ of all interactions. Modularity is 0.76 , indicating a high degree of separation among clusters as well. These findings suggest that the Air Show network resembles a brand driven network with a small number of groups that dominate the narratives. By contrast, the destination network resembles a community network with a broader distribution of clusters. There is a significant amount of overlap between the location and festival networks as $2 / 3$ of all air show narratives or 1481 twitter users contributed to both information networks .

RQ2 Who are the critical stakeholders in these hubs?

To identify critical hub stakeholders, measures of each user's connections and position in the network were calculated. These measures include in-degree centrality or the number of relationships directed toward a user and the betweeness centrality or the relative importance in the network. The twitter profiles of the top 20 users based on the highest indegree centrality were archived and used to classify the overall group. This metric was used as it indicates the importance of the user in the hub based on activity 
during the period of evaluation (Kilduff \& Krackhardt, 1994). Appendix 1 provides examples of the summarized profiles for Group 1 of the destination and the event.

RQ3: Topics discussed in hubs

The topics discussed in these groups were analyzed using text-mining software. The content of tweets in each group was extracted and processed using Voyant to identify commonly used words and phrases. This data was aggregated into themes presented below:

Table 1: Group Discussion Themes

\begin{tabular}{|l|l|l|}
\hline $\begin{array}{l}\text { Group } \\
\text { Number }\end{array}$ & $\begin{array}{l}\text { Bournemouth Location Main } \\
\text { themes }\end{array}$ & $\begin{array}{l}\text { Bournemouth Air Festival Main } \\
\text { Themes }\end{array}$ \\
\hline 1 & $\begin{array}{l}\text { Content Discussed in Hubs } \\
\text { Dominated by conversations } \\
\text { about the air festival and } \\
\text { related issues. Over } 2 / 3^{\text {rd }} \text { s of } \\
\text { the Air Festival's verticies } \\
\text { are contained within Group } 1\end{array}$ & $\begin{array}{l}\text { Domint Discussed in Hubs } \\
\text { by Bournemouth Media }\end{array}$ \\
\hline 2 & $\begin{array}{l}\text { Football Related topics of } \\
\text { discussion including rival } \\
\text { teams and players. }\end{array}$ & $\begin{array}{l}\text { Dominated by discussions of Night Air } \\
\text { Concert staged as part of the Air } \\
\text { Festival }\end{array}$ \\
\hline 3 & $\begin{array}{l}\text { Narratives on Music related } \\
\text { topics. Fans and Performers } \\
\text { at Night Air and other music } \\
\text { acts }\end{array}$ & $\begin{array}{l}\text { Bournemouth media discussions of } \\
\text { non air festival topics }\end{array}$ \\
\hline 4 & $\begin{array}{l}\text { Discussion of location by } \\
\text { visitors to Air festival }\end{array}$ & $\begin{array}{l}\text { Fans of bands and performers at } \\
\text { Night Air Concert }\end{array}$ \\
\hline 5 & $\begin{array}{l}\text { Discussions on events and } \\
\text { parties in the Bournemouth } \\
\text { Location. Service providers, } \\
\text { minor celebrities }\end{array}$ & Bournemouth Blog community \\
\hline
\end{tabular}

The key words that infer a location were explored further using a Keyword in Context tool to understand the way in which the term was used. Two examples are below:

Finally, findings from the content analysis and text analysis were integrated into table 1 to classify the hubs by content and user characteristics. 
Table 2: Group Classification compared

\begin{tabular}{|c|c|c|c|c|}
\hline \multirow{2}{*}{$\begin{array}{l}\text { GROUP } \\
\text { NO }\end{array}$} & \multicolumn{2}{|c|}{ Bournemouth Location } & \multicolumn{2}{|c|}{ Bournemouth Air Festival } \\
\hline & $\begin{array}{l}\text { Characteristics } \\
\text { of Users in Hubs }\end{array}$ & $\begin{array}{l}\text { Location of } \\
\text { Users in Hubs }\end{array}$ & $\begin{array}{l}\text { Characteristics of } \\
\text { Users in Hub }\end{array}$ & $\begin{array}{l}\text { Location of } \\
\text { Users in Hubs }\end{array}$ \\
\hline 1 & $\begin{array}{l}\text { Bournemouth } \\
\text { residents and } \\
\text { users }\end{array}$ & $\begin{array}{l}\text { Bournemouth } \\
\text { region (Dorset) } \\
\text { terms } \\
\text { mentioned most } \\
\text { often. Little } \\
\text { evidence of } \\
\text { users from } \\
\text { outside UK }\end{array}$ & $\begin{array}{l}\text { Official } \\
\text { Bournemouth } \\
\text { media accounts } \\
\text { and personal } \\
\text { twitter accounts of } \\
\text { media personnel }\end{array}$ & $\begin{array}{l}\text { Bournemouth } \\
\text { region (Dorset) } \\
\text { terms } \\
\text { mentioned most } \\
\text { often. Little } \\
\text { evidence of } \\
\text { users from } \\
\text { outside UK }\end{array}$ \\
\hline 2 & $\begin{array}{l}\text { Fans of football } \\
\text { teams }\end{array}$ & $\begin{array}{l}\text { Highly } \\
\text { international. } \\
\text { Dominated by } \\
\text { users from } \\
\text { Europe. }\end{array}$ & Music fans & $\begin{array}{l}\text { Bournemouth } \\
\text { region (Dorset) } \\
\text { terms } \\
\text { mentioned most } \\
\text { often. Little } \\
\text { evidence of } \\
\text { users from } \\
\text { outside UK }\end{array}$ \\
\hline 3 & $\begin{array}{l}\text { Official band } \\
\text { accounts and } \\
\text { accounts of fans }\end{array}$ & $\begin{array}{l}\text { Highly } \\
\text { international. } \\
\text { Dominated by } \\
\text { users from } \\
\text { Europe. }\end{array}$ & $\begin{array}{l}\text { Bournemouth } \\
\text { media }\end{array}$ & $\begin{array}{l}\text { Bournemouth } \\
\text { region (Dorset) } \\
\text { terms } \\
\text { mentioned most } \\
\text { often. Little } \\
\text { evidence of } \\
\text { users from } \\
\text { outside UK }\end{array}$ \\
\hline 4 & $\begin{array}{l}\text { Discussion of } \\
\text { location by } \\
\text { performer } \\
\text { (Westlife, } 40 \% \text { of } \\
\text { terms) and } \\
\text { visitors to Air } \\
\text { festival. } \\
\text { Mentions made } \\
\text { of the beach, } \\
\text { sunshine and } \\
\text { food }(<1 \%) \text {. }\end{array}$ & $\begin{array}{l}\text { Dominated by } \\
\text { non } \\
\text { Bournemouth } \\
\text { UK residents }\end{array}$ & Fans of bands & $\begin{array}{l}\text { Bournemouth } \\
\text { region (Dorset) } \\
\text { terms } \\
\text { mentioned most } \\
\text { often. Little } \\
\text { evidence of } \\
\text { users from } \\
\text { outside UK }\end{array}$ \\
\hline 5 & $\begin{array}{l}\text { Accounts of } \\
\text { service } \\
\text { providers, event } \\
\text { organizers, } \\
\text { venues }\end{array}$ & $\begin{array}{l}\text { Dominated by } \\
\text { Bournemouth } \\
\text { and UK } \\
\text { residents }\end{array}$ & $\begin{array}{l}\text { Accounts of } \\
\text { support services, } \\
\text { charities }\end{array}$ & $\begin{array}{l}\text { Bournemouth } \\
\text { region (Dorset) } \\
\text { terms } \\
\text { mentioned most } \\
\text { often. Little }\end{array}$ \\
\hline
\end{tabular}




\begin{tabular}{|l|l|l|l|}
\hline & & $\begin{array}{l}\text { evidence of } \\
\text { users from } \\
\text { outside UK }\end{array}$ \\
\hline
\end{tabular}

\section{ANALYSIS AND DISCUSSION}

While events are increasingly used to promote destinations, sufficient research attention has not been allocated to this trend to date. This study therefore attempts to fill the gap by examining the online narratives created by a destination and an event to understand the effect of the event on the topics discussed by stakeholders.

Earlier research has identified destination image and tourists overall destination attitude as drivers of future visits (Chi and Qu 2008, Kim, and Im 2011). Events aim to enhance the unique aspects of the destination in an attempt to enhance TDI and influence destination image. This research sought to examine the effect of an event on TDI using the example of the Bournemouth Air Festival and the Bournemouth location.

This research applies a new method combining SNA and text analysis to evaluate the narratives in the emergent Community of Interest around the destination and event. This approach can create deep insights from a large number of discussions, a property that conventional approaches lack. Further, it was able to adopt a data driven approach to inquiry that enabled subsequent analysis steps to be guided by earlier findings. In this way, the findings are based on the context that was examined. The analysis was able to uncover the extent to which the festival created eWoM around the destination along with the content of discussions.

The open nature of online platforms enable the engagement of a wide range of stakeholders, a pattern of behaviour that is evident here. Findings suggest that twitter users do form distinct clusters while discussing the Bournemouth Air Show and destination related topics. The modularity metric indicates that both the destination and air festival twitter communities are composed of distinct interest areas in which users are more engaged with each other than with others. This results supports the findings from previous research on political engagement and indicate that twitter can be used as 
a platform for identifying heterogeneous stakeholder interests. This property enables the dimensioning and analysis of both online communities of interest and three dimensions may provide a useful basis for comparision: the size (volume of tweets), span (pattern of topic engagement) and scope (geographic range of engaged stakeholders).

The size (volume of tweets)

Overall, the relatively low volume of tweets that directly mention the festival $(>3,000)$ as compared to the search term $(>30,000)$ may suggest that the Air Show did not have a very strong presence in online discussions about the destination when it was staged. Specifically, when compared to the estimated festival visitor numbers of $>1,000,000$, as compared to the annual visitor numbers of $5,000,000$ for the town, this number seems relatively low. However, text analysis of the discussions in the destination search term indicated the strong presence of festival related terms. Further, when aspects of destination were frequently mentioned, for example the beach, it was as a result of a discussion initiated by a performer at the festival or in the context of an event activity. Therefore, while direct discussions about the festival were relatively low, the festival influenced discussions about the destination. This suggest that similar to previous research where events act as an animator of existing facilities, events' influence extend online to act as an animator of online discussions about a destination, influencing TDI.

\section{Scope}

There is a significant amount of overlap between the location and festival networks as 2/3 of all air show narratives or 1481 twitter users were contained in both information networks (RQ1). The Air Show stream is dominated by local media agencies and local stakeholders promoting products and services (RQ2). This is confirmed by the analysis of the topics within the discussion (RQ3): the destination stream is characterized by general discussion topics by visitors and residents such as football and local events, while the Air Show stream had a significant component of coverage by Bournemouth Media. It indicates that the festival had a local focus, which is not in alignment with it's media promotion as an international event. The air show is in contrast to the destination network in which tourists and residents dominate the discussion. Further, the 
destination network has attracted far more overall engagement from twitter users located outside of Dorset. However, the influence of the festival on the destination narratives suggests that the while the festival did directly attract tourist attention, it did act as a means to influence perceptions about the destination.

\section{The span (pattern of topic engagement)}

Further, online engagement of the Air Show followed a "broadcast" pattern in which a few official stakeholders shaped the conversation and content (Himelboim et al., 2013). This indicates that twitter was simply used as another media platform to distribute official content about the air show and that there was little direct engagement or interest by online users. However, the destination network had a broader range of interests and a heterogeneous mix of stakeholders that include media, visitors and local community members. This comparison of patterns of engagement suggests that the Air Festival stimulated limited direct eWOM about the destination. Further, the international research of destination network, may mean that the Festival did reach an international online audience and may have acted as a place maker and image builder for the destination,

\section{Theoretical and Practical Contribution}

The findings make both theoretical and practical contributions. The first theoretical contribution is the confirmation that stakeholders form coherent communication and content clusters when discussing event and destination related topics on twitter. This finding is similar to earlier research on politics (HerdaĞdelen et al., 2013) and health related issues and it enables the potential application of analytical techniques from those domains to examine destination image. For researchers in the Marketing and Tourism domain, this finding is useful as it suggests that the technique can be applied further to examine complex phenomena such as Firm- Customer engagement in brand communities(Cova \& White, 2010). As the process adopts a census approach, it may be useful at identifying characteristics of subgroups within these communities that may be overlooked by convenience or probability sampling of survey based methodologies. 
The second is that events perform an animator role in both the offline and online domain. This is an extension to existing work that suggests that events act as an animator to enhance the unique aspects of destinations and improve TDI(O'Sullivan \& Jackson, 2002). This finding also indicates that since events are a significant component of a destination's traffic when staged and that events act to stimulate discussions in the main destination network, future research may opt to simply monitor the destination social media search terms and it may not be necessary to monitor event traffic separately.

Finally, the 3 S (Scale, Scope and Span) framework that can be used to compare destination related communities of interests. Current events and festivals research is constrained by the implicit assumption that all events are unique (Getz et al., 2010). However, the $3 \mathrm{~S}$ framework suggests that the online presence of a festival may be a useful basis of comparison.

For industry stakeholders, it may be necessary to take a holistic view of the online engagement created by the event and examine direct interactions from the event as well as the ones encouraged in the wider destination conversation. Current practice monitors crude numerical metrics such as number of tweets as proxies for engagement, which may be misleading, or even worse, fraudulent. Adoption of more sophisticated approaches incorporating SNA may provide a more accurate picture of online engagement, resulting in actionable insights for the firm. Finally, for destinations wishing to reach international audiences via events, it may be necessary to incorporate explicit international elements such as international performers in order to encourage a wider geographic span of impact.

\section{IMPLICATIONS:}

Bournemouth festival one of the collaborations between emergency service. Weather is unpredictable and requires last minute adjustment. Twitter is a very useful platform to do so. 
Analysis before the event to aid better forecasting of demand and better prediction of behaviours, better understanding of needs.

Analysis during the event to aid in crowd control due to weather changes along with real time sharing of information and content with advertisers.

After the event, Sharing content and images, starting the cycle for next year, promoting the event. 


\section{REFERENCES}

Adjei, M. T., Noble, S. M., \& Noble, C. H. (2010). The influence of C2C communications in online brand communities on customer purchase behavior. Journal of the Academy of Marketing Science, 38(5), 634-653. doi: http://dx.doi.org/10.1007/s11747-009-0178-5

Bagozzi, R. P., \& Dholakia, U. M. (2006). Open source software user communities: A study of participation in Linux user groups. Management science, 52(7), 1099-1115. doi: http://dx.doi.org/10.1287/mnsc.1060.0545

Baloglu, S., \& McCleary, K. W. (1999). A model of destination image formation. Annals of tourism research, 26(4), 868-897.

Blackshaw, P., \& Nazzaro, M. (2006). Consumer-generated media (CGM) 101: Word-of-mouth in the age of the web-fortified consumer. A Nielsen BuzzMetrics White Paper, Second Edition, Spring.

Borgatti, S. P., Mehra, A., Brass, D. J., \& Labianca, G. (2009). Network analysis in the social sciences. science, 323(5916), 892-895. doi: 10.1126/science.1165821

Brown, J. S., \& Duguid, P. (2001). Knowledge and organization: A social-practice perspective. Organization science, 12(2), 198-213. doi: http://dx.doi.org/10.1287/orsc.12.2.198.10116

Bruns, A., \& Stieglitz, S. (2012). Quantitative approaches to comparing communication patterns on Twitter. Journal of Technology in Human Services, 30(3-4), 160-185. doi: 10.1080/15228835.2012.744249

Carrington, P. J., Scott, J., \& Wasserman, S. (2005). Models and methods in social network analysis: Cambridge university press.

Casaló, L. V., Flavián, C., \& Guinaliu, M. (2008). Promoting consumer's participation in virtual brand communities: a new paradigm in branding strategy. Journal of Marketing Communications, 14(1), 19-36. doi: 10.1080/13527260701535236

Dellarocas, C., \& Narayan, R. (2006). A statistical measure of a population's propensity to engage in postpurchase online word-of-mouth. Statistical Science, 21(2), 277-285. doi: 10.1214/088342306000000169

Dugué, N., \& Perez, A. (2014). Social capitalists on Twitter: detection, evolution and behavioral analysis. Social Network Analysis and Mining, 4(1), 1-15. doi: 10.1007/s13278-014-0178-4

Echtner, C. M., \& Ritchie, J. B. (1991). The meaning and measurement of destination image. Journal of tourism studies, 2(2), 2-12.

Elliot, S., Papadopoulos, N., \& Kim, S. S. (2011). An integrative model of place image exploring relationships between destination, product, and country images. Journal of travel research, 50(5), 520-534.

Gergen, K. J. (2008). 22 Mobile Communication and the Transformation of the Democratic Process. Handbook of mobile communication studies, 297.

Getz, D. (2008). Event tourism: Definition, evolution, and research. Tourism management, 29(3), $403-$ 428. doi: 10.1016/j.tourman.2007.07.017 
Getz, D., Andersson, T., \& Carlsen, J. (2010). Festival management studies: developing a framework and priorities for comparative and cross-cultural research. International Journal of Event and Festival Management, 1(1), 29-59. doi: 10.1108/17852951011029298

Gold, J. R., \& Gold, M. (2005). Cities of culture: staging international festivals and the urban agenda, 1851-2000. Aldershot: Ashgate Publishing, Ltd.

Graeff, E., Stempeck, M., \& Zuckerman, E. (2014). The battle for 'Trayvon Martin': Mapping a media controversy online and off-line.

Graesser, A. C., Jeon, M., Yan, Y., \& Cai, Z. (2007). Discourse cohesion in text and tutorial dialogue. Information Design Journal, 15(3), 199-213. doi: http://dx.doi.org/10.1075/idj.15.3.02gra

Guerrero-Solé, F., \& Fernández-Cavia, J. (2013). Activity and Influence of Destination Brands on Twitter: A Comparative Study of Nine Spanish Destinations Information and Communication Technologies in Tourism 2014 (pp. 227-236): Springer.

Gwinner, K. (1997). A model of image creation and image transfer in event sponsorship. International marketing review, 14(3), 145-158. doi: 10.1108/02651339710170221

Hamid-Turksoy, N., Kuipers, G., \& Van Zoonen, L. (2013). "Try A Taste of Turkey" An analysis of Turkey's representation in British newspapers' travel sections. Journalism Studies(ahead-of-print), 1-16. doi: 10.1080/1461670X.2013.857479

Hardin, M. (2014). Moving Beyond Description Putting Twitter in (Theoretical) Context. Communication \& Sport, 2167479514527425.

Harwood, T., \& Garry, T. (2010). 'It's Mine!' - Participation and ownership within virtual co-creation environments. Journal of Marketing Management, 26(3-4), 290-301. doi: $10.1080 / 02672570903566292$

Hauben, M., \& Hauben, R. (1997). Netizens: On the History and Impact of Usenet and the Internet'IEEE Computer Society. ISBN, 818677066, 1997.

HerdaĞdelen, A., Zuo, W., Gard-Murray, A., \& Bar-Yam, Y. (2013). An exploration of social identity: The geography and politics of news-sharing communities in twitter. Complexity, 19(2), 10-20. doi: 10.1002/cplx.21457

Himelboim, I., Smith, M., \& Shneiderman, B. (2013). Tweeting apart: Applying network analysis to detect selective exposure clusters in Twitter. Communication Methods and Measures, 7(3-4), 195-223. doi: $10.1080 / 19312458.2013 .813922$

Hogan, B., Carrasco, J. A., \& Wellman, B. (2007). Visualizing personal networks: Working with participant-aided sociograms. Field Methods, 19(2), 116-144. doi: 10.1177/1525822X06298589

Huberman, B., Romero, D. M., \& Wu, F. (2008). Social networks that matter: Twitter under the microscope. First Monday, 14(1).

Humphreys, L., Gill, P., \& Krishnamurthy, B. (2013). Twitter: a content analysis of personal information. Information, Communication \& Society (ahead-of-print), 1-15.

Kietzmann, J. H., Silvestre, B. S., McCarthy, I. P., \& Pitt, L. F. (2012). Unpacking the social media phenomenon: towards a research agenda. Journal of Public Affairs, 12(2), 109-119. doi: 10.1002/pa.1412

Latour, B. (2005). Reassembling the social-an introduction to actor-network-theory. Reassembling the Social-An Introduction to Actor-Network-Theory, by Bruno Latour, pp. 316. Foreword by Bruno Latour. Oxford University Press, Sep 2005. ISBN-10: 0199256047. ISBN-13: 9780199256044, 1.

Lee, C.-K., Lee, Y.-K., \& Lee, B. (2005). Korea's destination image formed by the 2002 World Cup. Annals of tourism research, 32(4), 839-858.

Leech, N. L., \& Onwuegbuzie, A. J. (2007). An array of qualitative data analysis tools: A call for data analysis triangulation. School Psychology Quarterly, 22(4), 557. 
Lim, Y., Chung, Y., \& Weaver, P. A. (2012). The impact of social media on destination branding Consumer-generated videos versus destination marketer-generated videos. Journal of Vacation Marketing, 18(3), 197-206. doi: 10.1177/1356766712449366

Loader, B. D., Vromen, A., \& Xenos, M. A. (2014). The networked young citizen: social media, political participation and civic engagement. Information, Communication \& Society, 17(2), 143-150. doi: 10.1080/1369118X.2013.871571

Ma, M., \& Agarwal, R. (2007). Through a glass darkly: Information technology design, identity verification, and knowledge contribution in online communities. Information Systems Research, 18(1), 42-67.

Mangold, W. G., \& Faulds, D. J. (2009). Social media: The new hybrid element of the promotion mix. Business horizons, 52(4), 357-365.

McKenna, K. Y., \& Bargh, J. A. (2000). Plan 9 from cyberspace: The implications of the Internet for personality and social psychology. Personality and social psychology review, 4(1), 57-75.

McLeod, L., Doolin, B., \& MacDonell, S. G. (2012). A Perspective-Based Understanding of Project Success. Project Management Journal, 43(5), 68-86. doi: 10.1002/pmj.21290

McPherson, M., Smith-Lovin, L., \& Cook, J. M. (2001). Birds of a feather: Homophily in social networks. Annual review of sociology, 415-444.

Munar, A. M. (2011). Tourist-created content: Rethinking destination branding. International Journal of Culture, Tourism and Hospitality Research, 5(3), 291-305.

Muniz Jr, A. M., \& O'guinn, T. C. (2001). Brand community. Journal of consumer research, 27(4), 412-432.

Neuhofer, B., Buhalis, D., \& Ladkin, A. (2012). Conceptualising technology enhanced destination experiences. Journal of Destination Marketing \& Management, 1(1), 36-46. doi: 10.1016/j.jdmm.2012.08.001

Newman, M. E. (2001). Scientific collaboration networks. II. Shortest paths, weighted networks, and centrality. Physical review E, 64(1), 016132.

O'Sullivan, D., \& Jackson, M. J. (2002). Festival tourism: a contributor to sustainable local economic development? Journal of Sustainable Tourism, 10(4), 325-342. doi: 10.1080/09669580208667171

Obst, P., Zinkiewicz, L., \& Smith, S. G. (2002). Sense of community in science fiction fandom, Part 1: Understanding sense of community in an international community of interest. Journal of Community Psychology, 30(1), 87-103.

Oliver, P., Marwell, G., \& Teixeira, R. (1985). A theory of the critical mass. I. Interdependence, group heterogeneity, and the production of collective action. American journal of Sociology, 522-556.

Page, S., J., \& Connell, J. (2009). Event Tourism: Critical Concepts in Tourism (Vol. 1): Routledge.

Pettigrew, A. M. (1997). What is a Processual Analysis? Scandanavian Journal of Management, 13(4), 12.

Quinn, B. (2010). Arts festivals, urban tourism and cultural policy. Journal of Policy Research in Tourism, Leisure \& Events, 2(3), 264-279.

Rheingold, H. (1993). The virtual community: Finding commection in a computerized world: AddisonWesley Longman Publishing Co., Inc.

Rothaermel, F. T., \& Sugiyama, S. (2001). Virtual internet communities and commercial success: individual and community-level theory grounded in the atypical case of TimeZone. com. Journal of Management, 27(3), 297-312.

Schultze, U., \& Orlikowski, W. J. (2010). Research Commentary-Virtual Worlds: A Performative Perspective on Globally Distributed, Immersive Work. Information Systems Research, 21(4), 810821. doi: 10.1287/isre.1100.0321

Scott, J. (1988). Social network analysis. Sociology, 22(1), 109-127. 
Sevin, E. (2013). Places going viral: Twitter usage patterns in destination marketing and place branding. Journal of Place Management and Development, 6(3), 227-239. doi: 10.1108/JPMD-10-20120037

Smith, K. A. (2003). Literary enthusiasts as visitors and volunteers. International journal of tourism research, 5(2), 83-95. doi: 10.1002/jtr.419

Sun, M., Ryan, C., \& Pan, S. (2014). Using Chinese travel blogs to examine perceived destination image: the case of New Zealand. Journal of travel research, 0047287514522882. doi: $10.1177 / 0047287514522882$

Tufekci, Z. (2014). Big Questions for Social Media Big Data: Representativeness, Validity and Other Methodological Pitfalls. arXiv preprint arXiv:1403.7400.

Vega, E. L. (2011). Communities of Tweeple: How Communities Engage with Microblogging When Colocated. Virginia Polytechnic Institute and State University.

Voss, C., Tsikriktsis, N., \& Frohlich, M. (2002). Case research in operations management. International Journal of Operations \& Production Management, 22(2), 24. doi: 10.1108/01443570210414329

Weber, I., Garimella, V. R. K., \& Teka, A. (2013). Political hashtag trends Advances in Information Retrieval (pp. 857-860): Springer.

Wirtz, J., Den Ambtman, A., Bloemer, J., Horváth, C., Ramaseshan, B., Van De Klundert, J., . . . Kandampully, J. (2013). Managing brands and customer engagement in online brand communities. Journal of service Management, 24(3), 223-244. doi: 10.1108/09564231311326978

Wu, S., Hofman, J. M., Mason, W. A., \& Watts, D. J. (2011). Who says what to whom on twitter. Paper presented at the Proceedings of the 20th international conference on World wide web, Hyderabad, India.

Xiang, Z., \& Gretzel, U. (2010). Role of social media in online travel information search. Tourism management, 31(2), 179-188. doi: 10.1016/j.tourman.2009.02.016

Zaglia, M. E. (2013). Brand communities embedded in social networks. Journal of business research, 66(2), 216-223. doi: 10.1016/j.jbusres.2012.07.015 